\title{
On The Detriment Of Obsession With Individual Achievement In Cooperative Learning
}

\author{
William B. Joyce, (E-mail: wbjoyce@eiu.edu), Eastern Illinois University
}

\begin{abstract}
This research developed and tested a model of the relationship between detrimental behavior and cooperative learning. It is hypothesized that relationship between group and individual detrimental behavior would be strongest among those simultaneously high in individual consideration and abnormal behavior. The hypothesis was tested and replicated with statistically significant results. Implications are discussed and future research directions are identified.
\end{abstract}

\section{INTRODUCTION}

1

$\mathrm{n}$ recent years, researchers have increased their attention to social undermining and similar forms of antisocial behavior in organizations (Duffy, Shaw, Scott, and Tepper, 2006). People engage in socialundermining behavior when they behave in ways that are intended to hinder a targeted person's ability to establish and maintain positive interpersonal relationships, achieve work-related success, and maintain a favorable reputation (Duffy, Ganster, and Pagon, 2002). Although less serious than physical aggression, social-undermining behavior has damaging consequences in terms of negative job-related attitudes and behaviors and diminished wellbeing (Duffy et al., 2002). Social undermining resides on a separate and distinct continuum from positive workplace behaviors (social support); low levels of undermining refer to the absence of negative behavior rather than the presence of positive behavior (O'Leary-Kelly, Duffy, and Griffin, 2000). Although researchers have made much progress in understanding the consequences of undermining behaviors, Robinson and Greenberg (1998) concluded that the literature on the determinants of such behavior is not only sparse but also narrow. These authors challenged researchers to develop richer antecedent models that include interactions between persons and situations and to examine the transfer of antisocial behavior from individual to individual within an organization (Robinson and Greenberg, 1998). Accordingly, (a) the literature is reviewed and the hypothesis is developed that group undermining behavior relates to individual undermining behavior at a later point in time, (b) predicted that selfesteem would moderate the group undermining and individual undermining relationship, and (c) predicted that neuroticism would further moderate this relationship. This model was then tested both on different levels and different groups.

This research extends and synthesizes two lines of research. The first stream has shown that work groups that exhibit aggressive behaviors like social undermining shape an individual member's undermining behavior (Glomb and Liao, 2003). However, this research also suggests that not everyone who is exposed to group-level undermining behavior engages in the same types of behaviors; that is, individual difference variables may moderate this relationship. Moreover, existing research has failed to move beyond cross-sectional tests of the relationship; thus, researchers know little about how these dynamics unfold over time. The second stream of research has taken initial steps to explore the relationship between individual characteristics (such as self-esteem and neuroticism) and antisocial behavior, but these variables have typically been cast as main effects (Douglas and Martinko, 2001). General self-esteem (Baumeister, 1997) and neuroticism (Douglas and Martinko, 2001) have often been cited as important precursors, but existing results are inconsistent. Baumeister, Smart, and Boden (1996), concluded that results of studies of the relationship between self-esteem and antisocial behavior were ambiguous, contradictory, and inconsistent. Research on neuroticism, trait negative affectivity, and trait anxiety has likewise yielded contradictory results (Glomb and Liao, 2003). 
Studies that focus on individual characteristics and antisocial behaviors are also overwhelmingly conducted at the individual level; that is, they are focused on individuals' antisocial responses to being the specific target of antisocial behavior personal threats). Little, if any, research examines individual responses to general levels of antisocial or aggressive behavior in the environment. Cross-level research is warranted because individuals do not experience social undermining in a social vacuum, and the effects of individual difference variables depend on the environmental context (Duffy, Shaw, and Stark, 2000). Moreover, there are unique theoretical justifications for the roles of self-esteem and neuroticism in response to environments rife with undermining, as describe later. Thus, this theoretical approach concerns the roles of self-esteem and neuroticism, not in terms of whether an individual is personally targeted, but rather in terms of the level of undermining behavior present in the social context (Glomb and Liao, 2003).

To summarize, this research has explored the following question: What combinations of individual factors exacerbate or attenuate the relationship between group-level undermining and subsequent undermining behavior on the part of individuals? In the sections below, the theoretical foundation for the relationship between group and individual undermining behavior is briefly discussed. The predictions are developed concerning the moderating roles of self-esteem and neuroticism on the group and individual undermining relationship.

\section{LITERATURE REVIEW AND HYPOTHESES}

\section{Group And Individual Undermining}

The relationship between group and individual aggressive behavior like social undermining is typically grounded in social learning (Bandura, 1977) or social-information processing theory (Salancik and Pfeffer, 1978). As with many social behaviors, individuals may learn to engage in undermining behaviors by having direct experience with them or by observing and then modeling these behaviors (Bandura, 1973). Socialinformation processing theory suggests that individuals use cues in the social environment to guide their behaviors. These cues come in the form of values, norms, and expectations, as well as in the behaviors of coworkers and supervisors. In two recent studies, these ideas were applied to the relationship between group and individual antisocial behavior. Robinson and O'Leary-Kelly (1998), in a cross-sectional field study of various work groups from several different organizations, found that a measure of group antisocial behavior (with a content domain similar to that of social undermining) related positively to a parallel measure of individual antisocial behavior. Glomb and Liao (2003), in a study of assisted-living home employees, controlled for perceptions of being the target of nonviolent aggression and found that a group climate of nonviolent aggression predicted individual nonviolent aggression. These studies show the apparent robustness of the cross-level relationship between group and individual aggressive behaviors like social undermining at work and provide substantial support for the sociallearning and social-information processing perspectives. In line with these findings, it is expected that group-level and individual-level undermining behavior would also be positively related in this study. Thus, Hypothesis one was that there would be a positive relationship between the level of undermining in the group and the level of individual undermining behavior at a later time.

\section{The Moderating Role Of SE}

Researchers have often identified self-esteem (the overall evaluation that people make about themselves) as a potential predictor of antisocial behavior. Initially, researchers assumed individuals low in self-esteem were most likely to behave antisocially (Savin-Williams and Jaquish, 1981), perhaps because they are more critical of themselves and others (Baumeister, 1997). Yet, recent work suggests that high-SE individuals may be more likely to engage in antisocial behaviors than their low self-esteem counterparts (Kirkpatrick, Waugh, Valencia, and Webster, 2002). Thus, views and findings conflict as to whether low self-esteem or high self-esteem individuals are more aggressive.

Views also appear to conflict about how individuals with different levels of self-esteem may respond to a climate of group undermining by undermining their group members at a later time. But a close examination of Brockner's (1988) plasticity theory resolves this theoretical inconsistency. According to this theory, low self-esteem 
individuals are susceptible to influence by both external and social cues (Brockner, 1988) because they (a) are uncertain about the correctness of their thoughts and actions and rely on social cues to guide them, (b) have a higher need for approval from others relative to high-SE individuals, and (c) are more likely than high self-esteem individuals to believe that negative feedback is valid or self-diagnostic. Brockner (1988) also suggested that the work group is one of the most salient aspects of an individual's social environment. Although it would be reasonable to expect, then, that low self-esteem individuals are more strongly affected by high levels of group undermining and may engage in more social-undermining behavior compared with high self-esteem people, close examination of the theory suggests the opposite.

\section{High Self-Esteem And Esteem-Threatening Situations}

Despite the general malleability of the attitudes and behaviors of low self-esteem individuals (the plasticity hypothesis), Brockner (1988) suggested that in certain situations, high self-esteem individuals are expected to be more influenced by environmental conditions than their low self-esteem counterparts. In particular, Brockner (1988) argued that external cues that threaten one's positive self-image (referred to as esteem-threatening situations) may, paradoxically, have a greater impact on individuals whose self-esteem is high rather than low). Esteem-threatening situations include not only behaviors directed at a given individual (being the target of undermining), but also other environmental conditions that create uncertainty or trigger social comparisons (a high level of undermining in a group situation). Social-undermining behavior is designed to inhibit one's ability to maintain positive relationships, achieve high levels of performance, and maintain a favorable work-related reputation (Duffy et al., 2002). That is, it embodies the characteristics of an esteem-threatening situation.

Brockner (1988) also carefully outlined the types of behavioral reactions that may be expected from those with high and low SE in reaction to esteem-threatening situations. He suggested that high self-esteem individuals have more to lose in terms of their relative standing in a given situation, so they should be driven to behave in ways that protect their self-image. Using a resource-based analogy, Spencer, Josephs, and Steele (1993) argued that some individuals have higher levels of this important resource (esteem and typically act in ways designed to enhance it, to increase their comparative favorability, or to succeed in general. These arguments suggest that because high-SE individuals place high importance on instrumental goals, for example, relative status, favorable social comparisons, and behavioral confirmation (Ormel, Lindenberg, Steverink, and Verbrugge, 1999), they will behave more proactively in ways that either maintain or enhance their relative favorability in group situations. Although high selfesteem individuals could respond in a variety of ways in esteem-threatening situations, we argue that they are more likely than their low self-esteem counterparts to engage in social-undermining behavior as a way to maintain their status. Antisocial behaviors, such as social undermining, have been seen as proactive or instrumental forms of aggression (Dodge, 1991), that is, attempts to get what he/she wants by being aggressive (Salmivalli, 2001). Following Brockner's (1988) logic, it seems reasonable to expect that high self-esteem individuals may respond to an esteem-threatening situation by engaging in an instrumental form of aggression to get what they want: an enhancement of their self-image.

High self-esteem individuals are also more driven to protect their self-image in esteem-threatening situations that do not prescribe a particular or directed course of action (Brockner, 1988). Although a variety of behavioral options are possible in response to high group undermining levels, high self-esteem individuals should be more likely to engage in undermining because they are more confident in their opinions and less likely to fear reprisals if their undermining attempts are unsuccessful. When high self-esteem individuals respond to high levels of undermining in the social environment by undermining others, that act lowers others' favorability and performance levels and may effectively enable high self-esteem individuals to maintain their standing. 


\section{Low Self-Esteem And Esteem-Threatening Situations}

In contrast with high self-esteem individuals, low self-esteem individuals tend to view environmental negativity as self-diagnostic and, therefore, may not yield to group undermining influences by engaging in such behaviors themselves. By doing so, low self-esteem individuals are at greater risk for receiving negative evaluations, a problematic situation because they are dependent upon others to provide them with positive evaluations (Brockner, 1988). Brockner (1988) noted that when low self-esteem individuals are confronted with esteem-threatening situations, they can react by withdrawing (either psychologically or physically) from the task at hand. In Spencer et al.'s (1993) view, low self-esteem individuals have lower resource levels and respond in a manner designed to protect or defend what few resources they have. Consistent with this idea, Duffy et al. (2000) reasoned that because low self-esteem individuals have a high need for approval and a desire to win points with other group members, they would be less likely to participate in the interpersonal bickering associated with high-conflict groups. In support of their theory, Duffy et al. (2000) reported that low self-esteem individuals withdrew more frequently from group work situations characterized by high levels of relationship conflict, but were also able to maintain positive peerrated performance evaluations in these situations. Brockner's (1988) plasticity boundaries and the resource-based analogy also suggest that low-SE individuals may respond to environmental threats by taking a defensive, cautious, or modest position, one that reduces the likelihood of further failure or humiliation (Baumeister, 1997).

To summarize, a theoretical corollary of plasticity theory as well as recent empirical evidence suggest that high self-esteem individuals are more likely than their low self-esteem counterparts to commit undermining behaviors when exposed to a high-undermining climate. Thus, our Hypothesis 2 was that group undermining and self-esteem would interact to predict individual undermining behavior at a later time such that the positive relationship between group undermining and individual undermining would be stronger among high self-esteem individuals.

\section{The Role Of Neuroticism}

Salmivalli (2001) concluded that simply discussing high and low self-esteem is just not sufficient and encouraged researchers to further explore the consequences associated with potentially unhealthy and/or unstable self-esteem individuals. Extending her logic, there may be a subgroup of high self-esteem individuals who would be more prone to respond to group undermining by engaging in such behavior themselves. This research suggests that examining neuroticism concomitantly offers an avenue for exploring this logic and enhancing the predictive power of self-esteem in individuals' responses to group undermining.

Individuals high in emotional instability tend to exhibit poor adjustment and are prone to negative emotional states, including nervousness, anxiety, moodiness, and worry (Judge, Bono, Ilies, and Gerhardt, 2002). They also tend to interpret even neutral stimuli negatively (Lanyon and Goodstein, 1997). Gray (1981) further argued that a neuronal system (the behavioral inhibition system) regulates behavior in the presence of punishment signals, while the behavioral activation system regulates behavior in the presence of reward systems. Individuals differ in the relative strengths of these two systems with high neuroticism indicating a strong sensitivity to punishment signals in the environment (Begley and Lee, 2005). With these theoretical descriptors of neuroticism (that is, a general level of nervousness and worry and a heightened sensitivity to punishment signals), it is possible to establish a logical foundation for a three-way Group Undermining times self-esteem times neuroticism interaction.

Recall that high self-esteem individuals are in tune with external cues that may be esteem threatening, are more likely than those with low self-esteem to respond proactively to maintain or enhance their relative standing in the face of threats, and are less likely to fear reprisals in the form of negative evaluations from group members. When these characteristics of high self-esteem individuals are crossed with the descriptions of highneuroticism individuals, a clearer picture emerges of the interactive role of group-undermining levels, selfesteem, and neuroticism in predicting responses to group undermining. Higher levels of nervous worry and a stronger sensitivity to punishment signals, when combined with the high-SE characteristics described by Brockner (1988) and other scholars, should exacerbate the perception that undermining in the group may threaten one's relative status. Although high self-esteem/low-neuroticism individuals may be concerned about esteem threats in 
the environment, their dispositions, which desensitize them to punishment signals in the environment, should reduce the likelihood that they will interpret group undermining as an esteem threat or a potential interference in terms of achieving their instrumental goals. Undermining behaviors (belittling comments, giving someone the silent treatment, etc.) are often artfully crafted and quite subtle. While these individuals may be concerned with esteem threats, they may be less likely to pick up on the subtle undermining behaviors of others.

In contrast, the high self-esteem individual who has a strong sensitivity to punishment signals in the environment, a tendency to interpret social signals negatively, and a propensity to be worried and paranoid is more likely to engage in undermining behavior in response to the instrumental antisocial actions of others. Stated differently, the impetus to respond to an environment replete with undermining by turning the tables, attempting to maintain or enhance one's relative standing, or working to achieve other goals by engaging in undermining should be stronger among high self-esteem/high-neuroticism individuals. High self-esteem/low-neuroticism individuals are calmer and less sensitive to punishment signals and should not be as inclined to engage in undermining behavior in response to undermining behavior in the environment. Although not focused on neuroticism per se, some preliminary evidence provides initial clues that this formulation may hold. Kemis (1993), for example, found higher levels of hostility and anger among unstable high self-esteem individuals. Salmivalli (2001) concluded that unstable self-esteem individuals are more vulnerable to various types of provocations in the external environment, and Kernis, Grannermann, and Barclay (1989) found that stable, high self-esteem is associated with very low levels of aggression. Thus, Hypothesis three was that there would be a significant Group Undermining times self-esteem times neuroticism interaction in predicting individual undermining behavior at a later time, such that the positive relationship between group undermining and individual undermining would be strongest among individuals high in self-esteem and high in neuroticism.

\section{METHOD}

\section{Sample}

Participants were students enrolled in Managerial Accounting Principles sections at a state university. Participation was voluntary and confidentiality assurances were given. Various sections of the course, taught by different instructors, were involved. In all classes, the instructor required groups to complete several projects or assignments, and groups remained intact throughout the term. The group-grade portion of the class accounted for $20 \%$ to $25 \%$ of participants' total grade in the class. Instructors graded group assignments in absolute terms (a constant standard of achievement) rather than a relative standard (curved relative to other groups in the class). This distinction is important because this research is interested in isolating intra-group undermining behavior. When designing the study, it was considered important to minimize the possibility of and the motivation for inter-group undermining behavior. Data were collected at three points during the term. The first period collection was during the first week of class, before groups began to interact and complete projects. Control variables, self-esteem, and neuroticism measures were collected at period one. Period two data, including perceptions of group undermining behavior, were collected at midterm (eight weeks after period one). Period three data were collected just prior to final examinations (eight weeks after period two and sixteen weeks after period one). Individual reports of social-undermining behavior were collected at period three.

\section{Measures (Time Period Collected)}

Self-esteem in the first period was assessed with Rosenberg's (1965) ten-item scale. Scores on these dimensions were obtained with seven Likert-type response options. A sample item is "I feel I have a number of good qualities." Neuroticism in period one was measured with the twelve-item measure from Goldberg (1992). The items are in semantic differential format (at ease-nervous, discontented-contented) and had nine response options.

A seven-item measure adapted from Duffy et al.'s (2002) social-undermining measure was used in period two. Because of space and time constraints, it was necessary to use an abbreviated undermining measure; it was also necessary to adapt items to the group context. The items, as a group, reflect the nature of the definition of social 
undermining (that is, behaviors that diminish one's ability to establish and maintain positive interpersonal relationships, work-related success, and a favorable reputation). The items were formulated as questions. Participants were asked how often group members criticized them in front of other members, intentionally ignored them, talked down to them, went back on their word, gave them the silent treatment, belittled them or their ideas, or didn't listen to them. The items had response options from one (never) to seven (all the time).

Individual perceptions of undermining of group members were aggregated to the mean level in the group. Aggregation is appropriate because the referent for the items is the group's level of undermining behavior as perceived by a given group member. However, it was necessary to evaluate the appropriateness of aggregation empirically. Therefore, prior to aggregating this variable to the group level, the level of within-group agreement was assessed using the " $\mathrm{r}$ " formula from James, Demaree, and Wolf (1984). Aggregation to the group level was justified.

The dependent variable in the analyses, individual social-undermining behavior, was collected at period three. A seven-item scale also from Duffy et al.'s (2002) measure of social undermining was used. This measure focused on self-reports of one's own undermining behavior rather than reports of being the target of undermining. Sample questions are, "How often have you intentionally ignored team members?" and "How often have you intentionally given a team member the silent treatment?" The items had response options ranging from one (never) to seven (all the time).

Three potential confounds were controlled for: group size, grade point average (GPA), and individual reports of being the target of undermining. Group size may be related to group functioning (Duffy et al., 2000) and the incidence of undermining behaviors, and should be controlled. These data were collected from course instructors. GPA is a proxy for ability and may relate to reports of and reactions to undermining in groups. Selfreports of GPA (at period one) were used. Following Glomb and Liao (2003), perceptions of being the target of undermining were also controlled for. The hypotheses concern the influence of the undermining environment, over and above individual reports that others targeted them for undermining. This variable was the focal individual's reports on the seven-item undermining measure at period two.

\section{STATISTICAL RESULTS}

\section{Response Bias Checks And Measurement Issues}

To address the potential for response, self-selection, and attrition biases, a comparison of the participants in the final analysis sample with those who were eliminated because of missing data on a study variable across a range of demographic and expectation variables collected at period one. The variables were age, gender, GPA, number of prior classes taken with teamwork involved, class standing, and grade expectations for the class: "What grade will you 'shoot for' in this class?" Analysis-sample participants were coded as one and period-one only participants as zero, and included this dichotomy as the dependent variable in a logistic regression analysis with the predictors. None of the variables were significant in the equation. Therefore, it appeared that no systematic differences existed between retained and non-retained cases.

Research suggests that neuroticism and self-esteem may reflect a broad, latent, higher order trait, namely core self-evaluations (Judge, Locke, \& Durham, 1997). The bivariate correlations between these variables in this study were only moderate in magnitude, but because this study makes interactive predictions involving these constructs, it was necessary to assess whether our measures could be empirically differentiated. Confirmatory factor analysis was used to compare a two-factor model (items from the self-esteem and neuroticism measures loading on separate factors) with a one-factor or omnibus model that assumes the items represent a single construct. A chi-square difference test shows a significant improvement in model fit for a two-factor solution, and model fit statistics were also better for the two-factor solution than for the one-factor solution. 


\section{Hypothesis Tests}

The descriptive statistics and correlations among the study variables are shown in appendix one. Appendix two includes the results of the hypothesis tests. Because participants were nested in groups and the undermining independent variable was assessed at the group level, hierarchical linear modeling (HLM) was used to test the hypotheses. Before estimating the full equation, a null model was estimated with no predictors to partition variance into within-team and between-team components, and the degree of between-team variance in individual undermining was assessed. This analysis shows that there was systematic between-team variation in individual undermining. Moreover, using the interclass correlation coefficient formula provided by Hofmann, Griffin, and Gavin (2000), this analysis shows that $13.63 \%$ of the variance in individual undermining behavior resides between groups, and $86.37 \%$ resides within groups.

The test of hypothesis one (the main effect of group undermining at period two on individual undermining at period three) is a means as outcomes analysis in HLM (Raudenbush and Bryk, 2002). The level one model including controls, SE, neuroticism, and the self-esteem times neuroticism interaction is as follows:

$\alpha$ individual $=\beta+\mathrm{GPA}+$ target $+\mathrm{SE}+$ neuroticism $+€$

where, individual is individual undermining, GPA is grade point average, Target of undermining, SE is self esteem, AR is target of the results of the level one analysis demonstrated significant between-groups variance in undermining. This result justified analyses that included the level two group undermining predictor. The group undermining variable was included in a level two model:

$\alpha$ individual $=(1)+$ size + group $+€$

where, size is team size, and group is group undermining. The tests of the interaction hypotheses in HLM analysis involve the prediction of the slopes of the level one predictor variables. To satisfy the requirement of including all possible combinations of two-way interactions, the effect of group undermining on the SE and neuroticism was estimated, in addition to the effect of group undermining on SE times neuroticism was estimated. Thus,

$\alpha$ self-esteem $=\beta+$ group $+\epsilon$,

$\alpha$ neuroticism $=\beta+$ group $+\epsilon$, and

$\alpha$ self-esteem $*$ neuroticism $=\beta+$ group $+\mathrm{C}$.

where, $\mathrm{SE} *$ neuroticism is the combination of $\mathrm{SE}$ and neuroticism. Stated as a final or full mixed model including level one main effects, level two main effects, and cross-level interactions, the predicted equation is as follows:

$\alpha$ individual $\quad=\beta+$ GPA + size + target + group + self-esteem + neuroticism

+ group $*$ neuroticism + self-esteem $*$ neuroticism $+€$

\section{ANALYSIS}

Hypothesis one was that there would be a positive relationship between the level of undermining in the group and the level of individual undermining behavior at a later time. Among the control variables, only target of undermining (period two) was a significant predictor of individual undermining at period three. GPA and team size were not significantly related. Hypothesis one concerned the main effect cross-level relationship between group undermining at period two and individual undermining at period three. This relationship was positive and significant, as predicted. Thus, hypothesis one is supported. 
Hypothesis two (group undermining times self-esteem interaction in predicting individual undermining) was not supported. The effect of group undermining on the self-esteem individual undermining relationship was not significant.

The test of the three-way interaction prediction (the effect of group undermining on the self-esteem times neuroticism interaction) was significant. The relationship between group and individual undermining by levels of low and high self-esteem when neuroticism is low is not significant. When self-esteem is low, there is again a slightly positive but non-significant relationship between group undermining and individual undermining. When self-esteem is high, there is a significant positive relationship between group undermining and individual undermining. Also of note is that the highest levels of individual undermining are observed under the condition of high group undermining, high self-esteem, and high neuroticism. Thus, hypothesis three is supported.

\section{DISCUSSION}

Self-esteem and neuroticism were explored as moderators of the relationship between undermining behavior in a group and individual undermining behavior at a later time. The addition of variables that reflect stable individual characteristics (self-esteem and neuroticism) to existing theoretical frameworks concerning the transfer or spread of transgressive behavior in group situations provides several interesting insights to the undermining and individual difference literature. The investigation of group members over four months, the relationship between group and individual undermining behaviors was generally positive, but further analyses revealed that this relationship held only among individuals simultaneously high in self-esteem and neuroticism.

\section{Theoretical Implications}

This research suggests that three factors (social information processing, esteem-threatening social cues, and sensitivity to punishment signals in the environment) interact to produce the conditions under which individuals engage in undermining behaviors. Effects consistent with this framework were observed after controlling for individuals' perceptions that they were the target of group undermining. This may be interpreted to mean that individual undermining behaviors are more than just acts of revenge against other group members. It also increases the likelihood that (as argued in our theoretical foundation) these behaviors were responses, directed by transferred norms and values, intended to achieve instrumental goals such as relative status. In this study, the hypothesis (that high-SE individuals react more intensely to esteem-threatening situations) was supported. This research suggests that neuroticism plays an important role in undermining behavior, but as a moderating factor; specifically, undermining and self-esteem interacted consistently to predict individual undermining only among individuals characterized by dispositional negative emotionality and sensitivity to punishment signals. These findings provide insight into the psychological world of individuals in situations characterized by a surfeit of group undermining: emotional instability appears to trigger undermining behavior among those with generally positive self-evaluations.

\section{Practical Implications}

This research has implications for both education and management practice. Perhaps the most important implication has to do with the potential of studies like this to form the conceptual basis for interventions that are designed to reduce undermining behavior in both educational work organizations. Undermining and similar behaviors cost organizations significantly in terms of turnover, absenteeism, litigation, insurance, and diminished productivity (Sheehan, McCarthy, Barker, and Henderson, 2001). Consequently, there is considerable practical importance in conducting research that offers clues as to how and under what circumstances undermining behavior occurs. The results of this research suggest that situational interventions alone (instituting zero tolerance or enforcing severe punishments to offenders) will not be sufficient to eliminate undermining in work groups or to manage situations in which undermining behavior is normative. Managing undermining requires that decision makers understand the individual-based underpinnings of antisocial behavior. Specifically, decision makers should benefit from the knowledge that in the wake of group undermining, high-SE/high-neuroticism people will more likely engage in individual undermining behavior. Armed with such knowledge, decision makers can anticipate 
reactions to group undermining and arrest antisocial behaviors before they spread. Consistent with Glomb and Liao (2003), this research supports it may be more effective for organizations to design training programs around the issues of conflict management and the roles that individual-difference-based tendencies play in the performance of social-undermining behaviors.

\section{Future Research Directions And Research Limitations}

The results reported here suggest several potentially fruitful directions for future research. One promising avenue would be to disentangle, conceptually and empirically, the assumptions and mechanisms underlying theories of social-information processing, social learning, and attraction-selection-attrition. Another direction for future research involves focusing on group structure factors that may exacerbate or inhibit the spread of undermining from the group to individuals. Future researchers may consider undermining behaviors directed at out-group members. Also, are individual model undermining related to the level of power and prestige of those group members as well as the position of the group within the larger network of organizational relationships. Finally, leader behavior should be examined in the context of undermining.

This research has limitations. The use of student groups to simulate an actual group-based work environment could be seen as a shortcoming. Analyzing groups working in actual organizations, where organizational history and potential future interactions come into play, may produce different results. In addition, this research adapted undermining measures from prior research, which can raise questions regarding domain sampling and other validity issues.

\section{Appendix One \\ Panel One: Descriptive Statistics}

\begin{tabular}{lcc}
\hline \hline Variable & Mean & $\begin{array}{c}\text { Standard } \\
\text { Deviation }\end{array}$ \\
1. GPA (period one) & 3.32 & 0.41 \\
2. Narcissism (period one) & ---- & $---{ }^{-}$ \\
3. Team size & 4.46 & 0.72 \\
4. target of undermining (period two) & 1.28 & 0.42 \\
5. Group undermining (period two) & 1.26 & 0.24 \\
6. Self-esteem (period one) & 5.85 & 0.81 \\
7. Neuroticism (period one) & 3.89 & 0.96 \\
8. Individual undermining (period three) & 1.31 & 0.43 \\
\hline \hline
\end{tabular}

Dashes indicate that the values are not applicable. Team size was collected at the end of the semester.

Appendix One

Panel Two: Correlations

\begin{tabular}{|c|c|c|c|c|c|c|c|c|}
\hline Variable & 1. & 2. & 3. & 4. & 5. & 6. & 7. & 8. \\
\hline 1. GPA (period one) & & & & & & & & \\
\hline 2. Narcissism (period one) & ----- & & & & & & & \\
\hline 3. Team size & -.01 & & & & & & & \\
\hline 4. Target of undermining (period two) & $0.12 *$ & ----- & $0.11 *$ & & & & & \\
\hline 5. Group undermining (period two) & $0.17 * *$ & ----- & $0.17 * *$ & $0.45 * *$ & & & & \\
\hline 6. Self-esteem (period one) & -.06 & ----- & 0.01 & $-.18 * *$ & -.03 & & & \\
\hline 7. Neuroticism (period one) & 0.00 & ----- & 0.00 & $0.11 *$ & 0.01 & $-.38 * *$ & & \\
\hline 8. Individual undermining (period three) & 0.03 & ----- & 0.09 & $0.48 * *$ & $0.41 * *$ & -.04 & 0.04 & \\
\hline
\end{tabular}

$\mathrm{N}=333$. Dashes $=$ values are not applicable. Team size collected at semester end. $* \mathrm{p}<0.05 ; * * \mathrm{p}<0.01$. 
Hierarchical Modeling Result With Period Three Individual Undermining Behavior As The Dependent Variable

\begin{tabular}{|c|c|c|}
\hline \multirow[t]{2}{*}{ Independent Variable } & \multicolumn{2}{|c|}{$\begin{array}{c}\text { Individual Undermining } \\
\text { (period three) }\end{array}$} \\
\hline & Gamma & Standard Error \\
\hline \multicolumn{3}{|l|}{ Controls } \\
\hline GPA, period one (a) & -0.12 & 0.11 \\
\hline Team Size (b) & -0.01 & 0.07 \\
\hline Target of Undermining, period two (a) & $0.39 * *$ & 0.06 \\
\hline \multicolumn{3}{|l|}{ Independent Variables } \\
\hline Group Undermining, period two (b) & $0.81 * *$ & 0.26 \\
\hline Self-Esteem, period one (a) & 0.02 & 0.05 \\
\hline Neuroticism, period one (a) & 0.01 & 0.05 \\
\hline \multicolumn{3}{|l|}{ Interactions } \\
\hline Group-Undermining * Self-Esteem (c) & 0.23 & 0.19 \\
\hline Group-Undermining $*$ Neuroticism (c) & 0.01 & 0.21 \\
\hline Self-Esteem $*$ Neuroticism (a) & $0.07 *$ & 0.04 \\
\hline Group-Undermining $*$ Self-Esteem $*$ Neuroticism $(\mathrm{c})$ & $0.28 *$ & 0.14 \\
\hline
\end{tabular}

(a) level-one predictor, (b) level-two predictor, (c) cross-level interaction predictors. $* \mathrm{p}<0.05$; $* * \mathrm{p}<0.01$.

\section{REFERENCES}

1. Bandura, A., 1977. Social learning theory. Englewood Cliffs, NJ: Prentice Hall.

2. Bandura, A., 1986. Social foundations of thought and action: A social cognitive theory. Upper Saddle River, NJ: Prentice Hall.

3. Baumeister, R., 1997. Evil: Inside human cruelty and violence. New York: Freeman.

4. Baumeister, R., Smart, L., and Boden, J., 1996. Relation of threatened egoism to violence and aggression: The dark side of high self-esteem. Psychological Review, 103, 5-33.

5. Begley, T., and Lee, C., 2005. The role of negative affectivity in pay-at-risk reactions: A longitudinal study. Journal of Applied Psychology, 90, 382-388.

6. $\quad$ Brockner, J., 1988. Self-esteem at work. Lexington, MA: Lexington.

7. Dodge, K., 1991. The structure and function of reactive and proactive aggression. In D. Pepler \& K. Rubin (Eds.), The development and treatment of childhood aggression (pp. 201-218). Hillsdale, NJ: Erlbaum.

8. Douglas, S. C., \& Martinko, M. J., 2001. Exploring the role of individual differences in the prediction of workplace aggression. Journal of Applied Psychology, 86, 547-559.

9. Duffy, M. K., Ganster, D. C., \& Pagon, M. (2002). Social undermining in the workplace. Academy of Management Journal, 45, 331-352.

10. Duffy, M., Shaw, J., Scott, K., and Tepper, B., 2006. The moderating roles of self-esteem and neuroticism in the relationship between group and individual undermining behavior. Journal of Applied Psychology, 91, 1066-1077.

11. Duffy, M., Shaw, J, and Stark, E., 2000. Performance and satisfaction in conflicted, interdependent groups: When and how does self-esteem make a difference? Academy of Management Journal, 43, 772784.

12. Glomb, T., and Liao, H., (2003. Interpersonal aggression in work groups: Social influence, reciprocal, and individual effects. Academy of Management Journal, 46, 486-496.

13. Goldberg, L., 1992. The development of markers for the Big Five factor structure. Psychological Assessment, 4, 26-42.

14. Gray, J., 1981. A critique of Eysenck's theory of personality. In H. J. Eysenck (Ed.), A model of personality (pp. 246-276). New York: Springer.

15. Hofmann, D., Griffin, M., and Gavin, M., 2000. The application of hierarchical linear modeling to organizational research. In K. J. Klein \& S. W. J. Kozlowski (Eds.), Multilevel theory, research, and methods in organizations (pp. 467-511). San Francisco: Jossey-Bass. 
16. James, L., Demaree, R., and Wolf, G., 1984. Estimating within-group interrater reliability with and without response bias. Journal of Applied Psychology, 69, 85-98.

17. Judge, T., Bono, J., Ilies, R., and Gerhardt, M., 2002. Personality and leadership: A qualitative and quantitative review. Journal of Applied Psychology, 87, 765-780.

18. Judge, T., Locke, E., and Durham, C., 1997. The dispositional causes of job satisfaction: A dispositional approach. Research in Organizational Behavior, 19, 151-188.Kernis, M. (1993). The roles of stability and level of self-esteem in psychological functioning. In R. Baumeister (Ed.), Self-esteem: The puzzle of low self-regard (pp. 167-182). New York: Plenum Press.

19. Kernis, M., Grannermann, B., and Barclay, L., 1989. Stability and the level of self-esteem as predictors of anger arousal and hostility. Journal of Personality and Social Psychology, 56, 1013-1022.

20. Kirkpatrick, L., Waugh, C., Valencia, A., and Webster, G., 2002. The functional domain specificity of selfesteem and the differential prediction of aggression. Journal of Personality and Social Psychology, 82,

21. $756-767$.

22. Lanyon, R., and Goodstein, L., 1997. Personality assessment (3rd ed.). New York: Wiley.

23. O'Leary-Kelly, A., Duffy, M., and Griffin, R., 2000. Construct confusion in the study of antisocial behavior at work. Research in Personnel and Human Resources Management, 18, 275-303.

24. Ormel, J., Lindenberg, S., Steverink, N., and Verbrugge, L., 1999. Subjective well-being and social production functions. Social Indicators Research, 46, 61-90

25. Raudenbush, S., and Bryk, A., 2002. Hierarchical linear models: Applications and data analysis methods (2nd ed.). Thousand Oaks, CA: Sage.

26. Robinson, S., and Greenberg, J., 1998. Employees behaving badly: Dimensions, determinants, and dilemmas in the study of workplace deviance In C. Cooper and D. Rousseau (Eds.), Trends in organizational behavior (Vol. 5, pp. 1-30). Chichester, England: Wiley.

27. Robinson, S., and O'Leary-Kelly, A., 1998. Monkey see, monkey do: The influence of work groups on the antisocial behavior of employees. Academy of Management Journal, 41, 641-658.

28. Rosenberg, M., 1965. Society and the adolescent self-image. Princeton, NJ: Princeton University Press.

29. Salancik, G., and Pfeffer, J., 1978. A social information processing approach to job attitudes and task design. Administrative Science Quarterly, 23, 224-253.

30. Salmivalli, C., 2001. Feeling good about oneself, being bad to others? Remarks on self-esteem, hostility, and aggressive behavior. Aggression and Violent Behavior, 6, 375-393.

31. Savin-Williams, R., and Jaquish, G., 1981. The assessment of adolescent self-esteem: A comparison of methods. Journal of Personality, 49, 324-336.

32. Sheehan, M., McCarthy, P., Barker, M., and Henderson, M., 2001, July. A model for assessing the impacts and costs of workplace bullying. Paper presented at the Standing Conference on Organizational Symbolism, Trinity College, Dublin.

33. Spencer, S., Josephs, R., and Steele, C., 1993. Low self-esteem: The uphill struggle for self-integrity. In R. Baumeister (Ed.), Self-esteem: The puzzle of low self regard (pp. 21-36). New York: Plenum Press.

34. Tepper, B., and Taylor, E., 2003. Relationships among supervisors' and subordinates' procedural justice perceptions and organizational citizenship behaviors. Academy of Management Journal, 46, 97-105. 
NOTES 